\title{
El hábeas corpus como garantía constitucional para la protección de derechos fundamentales vulnerados por el hacinamiento carcelario*
}

\author{
Habeas Corpus as a constitutional guarantee for the protection of fundamental \\ rights violated by jail overcrowding
}

Diana Margarita Londoño López••

Fecha de recepción: 12 de octubre de 2018

Fecha de aprobación: 18 de enero de 2019

\section{RESUMEN}

En el presente trabajo se analizó el hábeas corpus como una garantía constitucional para la protección de derechos fundamentales vulnerados por el hacinamiento carcelario a la luz de la Ley Estatutaria 1095 de 2006. Para ello se indagó acerca de la evolución histórica de dicho principio, se analizó la normatividad nacional e internacional en concordancia con los pronunciamientos de la Corte Constitucional y se determinó el impacto del hacinamiento carcelario en los derechos fundamentales de los individuos privados de la libertad mediante la

* El presente artículo es producto del proyecto de investigación "El hábeas corpus como garantía constitucional para la protección de derechos fundamentales vulnerados por el hacinamiento carcelario", en el marco del programa de Pregrado en Derecho de la Universidad Santo Tomás Sede Medellín. Citar como Londońo López, D. (2019). El hábeas corpus como garantía constitucional para la protección de derechos fundamentales vulnerados por el hacinamiento carcelario. Via Inveniendi et Iudicandi, 14(2), 65-88. DOI: https://doi. org/10.15332/19090528.5044

** Abogada de la Universidad Santo Tomás Sede Medellín, Colombia. Correo electrónico: dianamll721@gmail. com. Orcid: https://orcid.org/0000-0002-8247-7210 
exposición de tendencias de política criminal contemporánea (politica criminal del enemigo, o populismo punitivo, y politica criminal minimalista o de los derechos humanos). Igualmente, se realizó un análisis del hacinamiento carcelario en Colombia estudiando causas y efectos en la población privada de la libertad, apoyado en estadísticas entregadas por el Inpec.

Lo anterior, permitió concluir que el Estado colombiano no está en capacidad de proporcionar protección integral a la población privada de la libertad y que el hacinamiento carcelario actual está vulnerando derechos fundamentales como la dignidad humana, la vida y la salud.

En aras de poner fin a tal vulneración, y en atención a lo recopilado en esta investigación, se determinó que es posible incoar el hábeas corpus para obtener la libertad de quien está sufriendo la vulneración — tal y como aconteció en Honduras, donde se concedió la libertad a siete presos al considerar la Corte Suprema de Justicia que sufrieron tratos crueles, inhumanos y degradantes - o en su defecto la prisión domiciliaria.

Palabras clave: hábeas corpus, hacinamiento carcelario, derechos fundamentales, populismo punitivo, política criminal. 


\section{Abstract}

In this work an analysis of Habeas Corpus was carried out. This purported to be a constitutional guarantee that protects fundamental rights, which are violated when overcrowding in jails happen, seen in light of the Ley Estatutaria 1095 de 2006. To achieve this, an inquiry about the evolution of Habeas Corpus was necessary in a national and international scale, which intended to analyze this normativity, along with the pronouncements made by the Constitutional Court regarding this matter. Through this inquiry, the impact of jail overcrowding was sentenced to be a condition that violates fundamental rights of convicted individuals. There was a presentation about tendencies in criminal contemporary politics (Criminal Politics of the Enemy or Punitive Populism and Criminal Politics). Also, there was a study on the causes and effects of jail overcrowding in Colombia by looking at statistics about jail inmates, which was provided by INPEC.

The aforementioned allowed to drawing the following the conclusion: The Colombian State is not in the capacity to provide integral protection to individuals in privation of their freedom. Jail overcrowding generates a violation of fundamental rights such as the human dignity, their lives, and their health.

For the sake of ending this violation of rights, and paying attention to what must be done according to the conclusion drawn from what was analyzed, it was determined that Habeas Corpus must be implemented to obtain liberty to any inmate suffering due to this plight. An example of this implementation happened in Honduras, where seven people were granted freedom when the Supreme Court of Justice determined that they were suffering from cruelties, degrading and inhumane treatment occurring in instances of jail overcrowding. Domiciliary imprisonment is another option as a possible solution to this problem.

Keywords: Habeas Corpus, jail overcrowding, fundamental rights, punitive populism, criminal politics. 


\section{INTRODUCCIÓN}

Los derechos fundamentales de quienes se encuentran privados de la libertad se ven vulnerados, entre otros factores, por el hacinamiento carcelario.

El hacinamiento genera problemas tales como inseguridad y criminalidad debido a la escasez de bienes y servicios básicos, lo que a su vez ha creado un mercado ilegal interno en el que se pone precio a las condiciones mínimas que el Estado está obligado a garantizar a los reclusos. Tratos crueles, inhumanos e indignos que llevan a la deshumanización de las personas, dadas las circunstancias en las cuales se encuentran dentro del centro de reclusión. Violación grave y sistemática del derecho a la salud debido a la situación de falta de higiene, insalubridad y la posibilidad de sufrir agresiones físicas y mentales (C. Const. Sentencia T-388/2013).

Así mismo, la Defensoría del Pueblo y la Oficina en Colombia del Alto Comisionado de las Naciones Unidas para los Derechos Humanos adelantaron una investigación en 2001, en la cual se corroboró, luego de realizar visitas de inspección a varios establecimientos carcelarios y penitenciarios del país, que el hacinamiento es un factor generador de violación de derechos fundamentales de quienes se encuentran privados de la libertad. Refiere la investigación: "En síntesis, a mayor hacinamiento, la calidad de vida de los reclusos y la garantía de sus derechos humanos y fundamentales es menor" (Alto Comisionado, 2001).

La privación de la libertad arbitraria es una situación que se configura al someter al interno a situaciones indignas e inadecuadas para su reclusión, las cuales van en contra de la Constitución y la Ley.

En la Ley 600 de 2000, arts. 382-389, que fueron declarados inexequibles por la Sentencia C-620 de 2001, se contemplaba la captura como momento de protección. Sin embargo, en la Ley Estatutaria 1095 de 2006, por medio de la cual se reglamentó el art. 30 de la Constitución, se reemplaza la expresión "capturado" por "privado de la libertad". Esto abre la posibilidad de exigir protección no solo al momento de la captura, sino también sobre las condiciones bajo las cuales el individuo se encuentra 
privado de la libertad. Es decir, el lugar en el cual se está haciendo efectiva la retención debe ser idóneo con el fin de asegurar el respeto de los derechos del capturado.

Aunque una persona se encuentre privada de la libertad tiene derecho a exigir por parte del Estado la protección de todos sus derechos, más aún por ser el mismo Estado el que tiene al recluso bajo su custodia y control. En este orden de ideas, se genera una relación entre la Nación y el preso denominada relación especial de sujeción, la cual es definida por López Benítez y acogida por la Corte Constitucional así:

Aquellas relaciones jurídico-administrativas caracterizadas por una duradera y efectiva inserción del administrado en la esfera organizativa de la administración, a resultas de la cual [sic] queda sometido a un régimen jurídico peculiar que se traduce en un especial tratamiento de la libertad y de los derechos fundamentales, así como de sus instituciones de garantía, de forma adecuada a los fines típicos de cada relación. (1994, p. 161)

El concepto de relación de sujeción especial nació en Alemania y su principal promotor fue Mayer (1982), quien la definió como “un estado de libertad restringida”.

La Corte Constitucional ${ }^{1}$ también se ha pronunciado sobre el tema y ha manifestado que, si el sistema penitenciario y carcelario no ofrece al recluso unas condiciones dignas _ en las cuales no solamente pague la pena impuesta, sino que, además, pueda ser preparado para la vida en libertad a través de la resocialización-, estará entonces sometido a una privación de la libertad arbitraria por cuanto no se cumple con las garantías constitucionales y legales que se han establecido para tal situación. Esto abre paso a la aplicación del hábeas corpus.

1 En reiteradas ocasiones, la Corte ha recurrido al concepto de relaciones especiales de sujeción, a efectos de analizar las relaciones existentes en términos de derechos y deberes entre las personas privadas de la libertad y las autoridades carcelarias. Respecto a las personas privadas de la libertad, las autoridades públicas: i) pueden limitar el ejercicio de algunos derechos fundamentales (intimidad, reunión, trabajo); ii) están imposibilitadas para limitar el ejercicio de determinados derechos fundamentales (vida, dignidad humana, debido proceso) y iii) tienen el deber dispositivo de asegurar el goce efectivo de los derechos fundamentales, en la parte que no sea objeto de limitación cuando proceda y en su integridad frente a los demás, debido a la especial situación de indefensión o de debilidad manifiesta en la que se encuentran los reclusos (C. Const. Sentencia T-023/2010). 


\section{EVOLUCIÓN HISTÓRICA DEL HÁBEAS CORPUS}

El hábeas corpus es una institución jurídica muy antigua que surgió como respuesta a la necesidad de protección de la libertad personal. Los antecedentes históricos analizados corresponden a la Antigua Grecia, el derecho romano, la legislación española, Estados Unidos y finalmente su aparición en Colombia (Pérez, 2013).

\section{Antigua Grecia}

La idea de libertad aparece por primera vez en Occidente en la Antigua Grecia a través de historiadores, filósofos y políticos, entre otros, quienes la presentaron como esencial para el desarrollo de la polis. Sin embargo, solo era defendida la de la clase económica y socialmente dominante. A pesar de ser la libertad un asunto de suma importancia para los griegos, el pensamiento político llevó a que se presentara una subordinación de los individuos frente al Estado, de modo que muchos eran afectados con la privación de este derecho, especialmente los esclavos y los metecos (extranjeros sobre quienes recaían muchas de las obligaciones de los ciudadanos, como el pago de impuestos ya que poseían riqueza, pero que no contaban con derechos políticos). La esclavitud fue justificada por personajes como Platón, Aristóteles y Cicerón (García, 1973).

\section{Roma}

El concepto de amparo de la libertad fue formalizado a través de los tribunos de la plebe (funcionarios con la facultad de ejercer el ius auxilii para defender a los plebeyos de las injusticias de los patricios). Luego se crean las leyes de Valerio Publícola, las cuales prohibían la pena corporal para aquellos ciudadanos que habían apelado la decisión del pueblo y admitían la custodia libera, que excluía toda prisión preventiva (García, 1973). Los mecanismos por medio de los cuales se protegía la libertad personal eran llamados interdictos y se presentaban al pretor para que decidiera sobre la situación de quien se encontraba privado de la libertad (Molina, 2016).

El derecho romano desarrolla la posibilidad procesal de hacer efectivo el hábeas corpus acudiendo al pretor, quien era el encargado de decidir sobre la solicitud. 
Igualmente, posibilitó que dicho recurso fuera interpuesto por un tercero sin necesidad de mandato, meramente exhibiendo al detenido y ordenando su libertad si se consideraba que su detención era injusta.

\section{España}

En la legislación española se resalta el inicio de la proclamación de la libertad como derecho del hombre en el Fuero de León, un pacto civil realizado entre el reino y don Alfonso IX en 1188. El pacto comprendía la libertad de forma negativa, como una limitación a las actuaciones de los gobernantes.

En 1527 se crea el Fuero de Vizcaya, que adoptó el principio de libertad personal para todos los vizcaínos, sin excepción, ordenando a sus magistrados respetar el principio y acatar la decisión del juez cuando lo protegía.

El reino de Aragón se destacó por contar con un pacto de tolerancia entre el rey y sus gobernados. El rey de Aragón nombró a un “justicia mayor de Aragón”, funcionario encargado de la defensa de la libertad y la seguridad civil aún en contra de las propias decisiones del monarca. Esto se materializaba a través de un juicio de manifestación, instituido en 1528, que en opinión del constitucionalista Linares Quintana constituye un verdadero antecesor del moderno hábeas corpus (García, 1973).

Finalmente, en 1566 se publica la recopilación de leyes del Reino de España Ley VII, título XXIII, libro 40 - . En ella se establecieron procedimientos para la detención y se determinó que su no cumplimiento acarrearía la libertad del detenido. Se constituyó, pues, en una garantía para la libertad personal.

\section{Estados Unidos}

La Declaración de Derechos realizada por los representantes del buen pueblo de Virginia (the good people of Virginia) proclama que los hombres cuentan con derechos inherentes y que son libres e independientes. Por lo tanto, no pueden ser privados de su libertad sino luego de la realización de un juicio justo y con la aplicación de leyes preestablecidas. 
En la Declaración de Independencia de 1776, y la posterior aprobación de la Constitución de los Estados Unidos de América en la Convención de Filadelfia en 1887, se incorporó el hábeas corpus, el cual era tenido en cuenta como un "privilegio" adoptado de las leyes inglesas, es decir, una concesión otorgada por la corona mas no un derecho (García, 1973).

El hábeas corpus ha sido suspendido en diversas ocasiones, incluso durante la presidencia de Lincoln en 1861. En la actualidad se da en dos niveles: federal y estatal, con algunas diferencias de tipo procesal y un campo de acción variado, lo que ha llevado a considerar que se presenta una desnaturalización de este derecho por no permitírsele su adecuado desarrollo en la aplicación de la justicia.

\section{Colombia}

Los antecedentes del hábeas corpus en nuestro país datan de 1863 con la expedición de la Constitución de los Estados Unidos de Colombia, en la cual se establecieron principios liberales adaptados de constituciones europeas. Posteriormente se promulgó la Constitución de 1886, que establecía en sus arts. 22 y 23 la prohibición de la esclavitud y la protección del derecho a la libertad individual respectivamente (Cárdenas, 2009). Ese mismo art. 23 dispuso los requisitos que debían cumplirse para la detención efectiva:

1. Que se decretara en virtud de mandamiento escrito de autoridad competente. No era suficiente una orden verbal.

2. Ser ejecutado con las formalidades legales.

3. Su justificación debía estar basada en leyes previamente existentes.

A pesar de haber tenido en cuenta la protección del derecho a la libertad individual y estipular requisitos para su ejecución, no se estableció un mecanismo a través del cual se hiciera efectivo el respeto de este derecho ni el tiempo que debía transcurrir para su solicitud. Por esta razón fueron negadas muchas solicitudes de hábeas corpus en casos de privación arbitraria de la libertad. 
Luego de la Constitución de 1886 se expidieron diversas normas de procedimiento penal en las que se regulaba el hábeas corpus. Tal es el caso del Decreto Ley 1358 de 1964, en el cual se delimitó por primera vez: quien se encontrase privado de la libertad por un lapso superior a 48 horas, considerando esa situación fuera de la ley podía acudir ante el juez penal municipal. Posteriormente, el Decreto 409 de 1971 —Código de Procedimiento Penal - lo reguló en sus arts. 417-422 en términos similares al decreto de 1964, pero adicionando la inimpugnabilidad del auto que decidiera sobre la solicitud.

Más adelante la Ley 600 de 2000 nuevamente reguló el hábeas corpus, esta vez en sus arts. 382-389. Sin embargo, dichos artículos fueron declarados inexequibles por la Sentencia C-620 de 2001 ya que por tratarse de un derecho constitucional no debía estar regulado por una norma ordinaria. Debido a esto se expide la Ley Estatutaria 1095 de 2006, reglamentaria del art. 30 de la actual Constitución Política.

\section{NORMATIVIDAD DEL HÁBEAS CORPUS}

\section{Normatividad internacional}

\section{Declaración Universal de los Derechos Humanos}

Fue aprobada el 10 de diciembre de 1948 por la Asamblea General de la ONU reunida en París. Establece las obligaciones y deberes de los Estados en relación con la promoción, el respeto y la protección de los derechos humanos.

\section{Pacto Internacional de Derechos Civiles y Políticos}

El Pacto fue adoptado por la Asamblea General de las Naciones Unidas a través de la Resolución 2200 A (XXI) el 16 de diciembre de 1966. Fue suscrito por Colombia el 21 de diciembre de 1966, se consagró en la legislación nacional mediante la Ley 74 de 1968 y entró en vigencia el 23 de marzo de 1976. Rescata la necesidad que la legislación del Estado Parte cuente con un mecanismo idóneo para verificar a la 
mayor brevedad posible si la privación de la libertad cumplió con las formalidades legales o de lo contrario se ordene la libertad.

\section{Convención Americana sobre Derechos Humanos}

Conocida como Pacto de San Joséz. Fue suscrita el 22 de noviembre de 1969 en San José de Costa Rica durante la celebración de la Conferencia Especializada Interamericana de Derechos Humanos y aprobada en Colombia mediante la Ley 16 de 1972. Esta última entró en vigencia a partir del 16 de julio de 1978.

\section{Normatividad nacional}

\section{Constitución Politica de Colombia}

La Carta Superior colombiana ha tenido en cuenta al hábeas corpus dándole una doble connotación: como derecho fundamental y como acción constitucional. Esto permite que los asociados cuenten con un mecanismo de protección contra los abusos y arbitrariedades a los que pueden ser sometidos por parte de las autoridades (Forero, 2014).

La base del hábeas corpus (Constitución Política de Colombia, 1991, art. 30) es la obligación de presentar al individuo privado de la libertad ante el juez de manera que se eviten detenciones ilegales o arbitrarias, lo cual garantiza el respeto a la libertad personal.

\section{Ley Estatutaria 1095 de 2006}

El hábeas corpus había sido regulado por normas ordinarias desde que fue tenido en cuenta por primera vez en el Decreto 1358 de 1964 hasta la Ley 600 de 2000. Pero los artículos de esta última fueron declarados inexequibles a través de la Sentencia C-620/2001 pues al definirse como derecho fundamental el principio allí contenido debía estar regulado mediante una Ley Estatutaria. Este tipo de leyes contemplan un

2 El hábeas corpus aparece allí descrito en los arts. 7 y 25. 
trámite especial que incluye la aprobación de la mayoría absoluta efectuada dentro de una sola legislatura, tal y como lo prevé el art. 153 de la Constitución Política.

La Ley 1095 de 2006 está compuesta por diez artículos en los cuales se dispone desde la definición del hábeas corpus hasta su vigencia.

\section{Análisis de la Sentencia C-187/2006}

A través de dicha sentencia se realiza la revisión previa de exequibilidad del Proyecto de Ley 284/02 Senado y 229/04 Cámara, con lo cual se da paso a la promulgación de la Ley Estatutaria 1095 de 2006 que reglamenta el art. 30 de la Constitución Política de Colombia.

Reconoce la Corte que el hábeas corpus es la garantía constitucional más importante para la protección del derecho a la libertad. Además, su naturaleza iusfundamental constituye una garantía no solo para este derecho, sino también para otros derechos fundamentales que pueden verse vulnerados por la privación de la libertad, tales como la vida y la integridad personal.

Es por ello que en la sentencia objeto de análisis se encuentran apartes en los cuales la Corte Constitucional ha dado vía libre a la utilización de este mecanismo para la protección de derechos fundamentales, como se observa en el siguiente párrafo:

La privación arbitraria o ilegal de la libertad de una persona, como se ha recordado, puede constituir una modalidad o medio para la violación de otros de sus derechos y libertades, los que se han colocado en condiciones precarias, o incluso pueden llegar a ser anulados en ciertos casos extremos. Por ello, la cabal protección del hábeas corpus reviste vital importancia, pues a través de este medio idóneo se protegen derechos como el de la vida e integridad de la persona privada de la libertad en cualquier circunstancia, lo cual impone el carácter sumario e inmediato de la protección que se pretende otorgar a través de este medio, ya que en muchos casos será urgente una decisión inmediata de libertad a fin de salvaguardar el conjunto integral de todos los derechos en 
juego, y con previa presentación del detenido ante el juez o tribunal competente para resolver el hábeas corpus.

Teniendo en cuenta que esta sentencia estudia el proyecto de ley que abrió paso a la promulgación de la ley estatutaria del hábeas corpus, se hará énfasis en el análisis de constitucionalidad del art. 1 por considerarse el sustento de la presente investigación.

El texto de la norma es el siguiente:

Artículo 1. Definición. El hábeas corpus es un derecho fundamental y, a la vez, una acción constitucional que tutela la libertad personal cuando alguien es privado de la libertad con violación de las garantías constitucionales o legales, o esta se prolongue ilegalmente. Esta acción únicamente podrá invocarse o incoarse por una sola vez y para su decisión se aplicará el principio pro homine.

El hábeas corpus no se suspenderá, aún en los Estados de excepción.

Se tienen en cuenta entonces dos escenarios en los cuales es posible recurrir a la acción de Hábeas corpus: i) cuando la persona es privada de la libertad con violación de las garantías constitucionales o legales y ii) cuando la privación de la libertad se prolonga ilegalmente.

Las garantías constitucionales o legales de que trata este artículo comprenden todos aquellos preceptos contenidos en la Constitución Política y en el ordenamiento jurídico que establezcan una limitación al poder público permitiendo una defensa contra el abuso de la autoridad. Estas garantías corresponden a una obligación del Estado de velar por el bienestar de sus asociados, más aún por el de quienes se encuentran privados de la libertad en razón de la sujeción especial que se crea entre estos y aquel. El hacinamiento carcelario vulnera las garantías constitucionales y legales pues el individuo es sometido a situaciones que atentan directamente contra la dignidad humana y otros derechos fundamentales.

Destaca la Corte algunas hipótesis bajo las cuales se ha de tener en cuenta el hábeas corpus, tales como ser privado de la libertad en lugar diferente al destinado oficialmente 
cuando no media mandamiento escrito de autoridad judicial competente, cuando no se cumple con las formalidades previstas en la ley "o por un motivo que no está definido en esta". La expresión enfatizada da cuenta de la posibilidad de instaurar la acción de protección en un evento que implique la vulneración de derechos fundamentales y que no haya sido tenido en cuenta en el proyecto de ley o en la sentencia misma. Más adelante se manifiesta que no es extraño que quien haga uso de la fuerza para privar de la libertad de forma irregular o arbitraria a otro también "la utilice para dar al retenido tratos crueles, inhumanos o degradantes, torturas, desaparecimiento e, inclusive, para atentar contra su vida”.

La acción de hábeas corpus para solicitar la excarcelación de quienes consideran vulnerados sus derechos fundamentales en razón de la incapacidad del Estado para proporcionar un lugar de reclusión digno se ha utilizado en países como Honduras. Allí John César Mejía, fiscal especial de Derechos Humanos, interpuso hábeas corpus en favor de siete detenidos de la Celda Veinte o Celda de Castigo de la Penitenciaría Nacional de San Pedro Sula (Departamento de Cortés), lo que llevó a que la Corte Suprema de Justicia, a través de su Sala Constitucional, ordenara la libertad de los referidos por considerar que se encontraban sometidos a tratos crueles, inhumanos y degradantes.

Por otra parte, en el foro Nuevo Estado de Cosas de Inconstitucionalidad - adelantado por el Ministerio de Justicia y del Derecho en la Facultad de Derecho, Ciencias Políticas y Sociales de la Universidad Nacional de Colombia el 9 de septiembre de 2015 - la comunidad académica y la ciudadanía en general reflexionaron sobre la Sentencia T-388/2013, que declara por segunda vez el estado de cosas inconstitucional en torno a la situación carcelaria. En ese sentido, el Dr. José Manuel Díaz Soto, defensor delegado para la Política Criminal y Penitenciaria de la Defensoría del Pueblo, sostuvo que

no hay nada que impida, vía un hábeas corpus correctivo, que un juez disponga que las personas que se encuentran en fase de mediana y mínima seguridad accedan a prisión domiciliaria, pese a que objetivamente no tengan los requisitos para ello. (Consejo Superior de Política Criminal, 2015, p.13) 
Con todo lo recopilado en esta investigación es posible establecer que la acción de hábeas corpus ha sido contemplada no solo para proteger el derecho a la libertad individual, sino también todos aquellos derechos que se derivan de este y que se ven vulnerados por las condiciones inapropiadas en las cuales puede estar quien se encuentre privado de la libertad.

\section{El hacinamiento CarCelario en COlombia}

El hacinamiento carcelario es una problemática mundial que ha generado graves crisis en muchos de los sistemas penitenciarios de países europeos y latinoamericanos, entre otros. En Colombia la mayoría de los establecimientos penitenciarios y carcelarios adolecen de sobrepoblación, lo que se traduce en condiciones indignas, inseguras e insalubres para quienes están privados de la libertad.

En la actualidad el Inpec cuenta con 135 establecimientos distribuidos en 6 regionales (Central, Occidente, Norte, Oriente, Noroeste y Viejo Caldas), con capacidad para albergar a 79172 presos. Sin embargo, la población privada de la libertad, a corte 24 de mayo de 2018, suma un total de 117 193, lo que representa una sobrepoblación de 38021 detenidos, equivalente a un $48.02 \%$ de hacinamiento.

\section{Causas del hacinamiento carcelario}

Son diversas las causas que explican el hacinamiento carcelario que se sufre en la actualidad. No obstante, se mencionarán solo las que han sido consideradas de mayor trascendencia para la crisis existente.

\section{El Instituto Nacional Penitenciario y Carcelario (Inpec)}

Dicha entidad es responsable del cuidado y vigilancia tanto de los condenados como de los sindicados. Al respecto es necesario hacer una aclaración: en los últimos años se ha evidenciado un incremento alarmante en el número de personas sometidas a prisión preventiva por estar inmersas en una investigación penal, lo que pone en entredicho temas como la presunción de inocencia y su manejo. 
Aunado a lo anterior, se presenta un déficit en la infraestructura carcelaria toda vez que no existen suficientes establecimientos penitenciarios y carcelarios para albergar a todos los reclusos, lo que genera un gran deterioro en las estructuras existentes. Así mismo, se advierte que en la actualidad no se están creando nuevos centros, y que aun creándolos no se lograría cobijar a toda esa población. En ese sentido, es necesario y pertinente manifestar que, como se ha demostrado en la presente investigación, se deben ejecutar otras acciones judiciales a fin de evitar que continúe la vulneración de los derechos humanos de los reclusos.

\section{Aumento de las conductas delictivas}

Otro factor importante para explicar el hacinamiento es el aumento de las conductas consideradas delictivas para las cuales se contempla la privación de la libertad. Al igual que el aumento de las penas existentes con ocasión de la entrada en vigencia de la Ley 890 de 2004, que adiciona y modifica el Código Penal incrementando las penas privativas de la libertad en una tercera parte las mínimas y en la mitad las máximas.

\section{El incremento de casos de privación arbitraria de la libertad y la falta de aplicación del hábeas corpus}

$\mathrm{Al}$ respecto, también se ha considerado que la privación arbitraria de la libertad y la falta de aplicación del hábeas corpus conllevan el hacinamiento carcelario o sobrecupo de presos en las cárceles del país. El resultado es el sometimiento de los reclusos a condiciones deplorables, crueles e inhumanas que vulneran sus derechos fundamentales.

\section{Populismo punitivo}

Es una situación que se ha tornado relevante pues a través de esta práctica se busca obtener beneficios de tinte político a costa de la vulneración de los derechos de quienes tienen que padecer las consecuencias de un sistema carcelario y penitenciario fallido. El llamado populismo punitivo hace referencia a la creación de nuevos tipos penales o el endurecimiento de las penas con la finalidad de ganar adeptos y votos. 


\section{Efectos del hacinamiento carcelario}

Tal y como se ha manifestado anteriormente, el hacinamiento carcelario tiene como efectos la inseguridad y criminalidad dentro de los establecimientos penitenciarios y carcelarios debido a la comercialización ilegal de productos y servicios necesarios para una estadía digna, los cuales deberían ser proporcionados por el Estado teniendo en cuenta la relación de sujeción que se presenta entre este y el sujeto privado de la libertad. También hace referencia la Sentencia T-388/2013 a la deshumanización de los reclusos como resultado de los tratos crueles e inhumanos a los cuales se encuentran sometidos. Por no hablar de los problemas de salubridad e higiene, entre otros.

Es válido resaltar que, como respuesta a la crisis penitenciaria que vive Colombia desde hace varios años, la Corte Constitucional ha decretado en dos oportunidades el estado de cosas inconstitucional mediante las sentencias T-153/1998 y T-388/2013. Esta última fue producto de la revisión a las decisiones judiciales de los jueces de tutela de instancia, quienes se pronunciaron sobre las acciones de tutela que propendían a la protección de derechos fundamentales vulnerados por el hacinamiento carcelario en seis establecimientos penitenciarios y carcelarios del país, a saber: i) Complejo Carcelario y Penitenciario Metropolitano de Cúcuta (Cocuc), ii) Cárcel La Tramacúa de Valledupar, iii) Cárcel Modelo de Bogotá, iv) Cárcel Nacional Bellavista de Medellín, v) Cárcel San Isidro de Popayán y vi) Establecimiento Penitenciario y Carcelario de Barrancabermeja. La Corte impartió órdenes específicas para los centros de reclusión anteriormente referidos y además planteó compromisos de carácter general que vinculan a todos los establecimientos del país.

\section{Concepto de política criminal}

La Corte Constitucional ha definido la política criminal como

el conjunto de respuestas que un Estado estima necesario adoptar para hacerle frente a conductas consideradas reprochables o causantes de perjuicio social con el fin de garantizar la protección de los intereses esenciales del Estado y de los derechos de los residentes en el territorio bajo su jurisdicción. (Sentencia C-646/2001) 
También manifiesta la Corte que la política pública en materia criminal comprende tres estadios, a saber:

i) Definición de sus elementos constitutivos y las relaciones entre ellos, ii) articulación inteligible de sus componentes, y iii) programación de la forma, los medios y el ritmo al cual será desarrollada dicha política; en ese orden de ideas, [...] las decisiones constitutivas del diseño de una política pública pueden ser plasmadas, o bien en documentos políticos, o bien en instrumentos jurídicos - esto es, normas, sean estas de rango constitucional, legal o reglamentario. (Sentencia C-936/2010)

La política criminal es una forma reflexiva de generar estrategias que permitan lograr los objetivos trazados en torno al combate contra la delincuencia.

\section{Tendencias contemporáneas de política criminal}

Es necesario analizar cómo se entiende la política criminal en el contexto actual refiriendo dos grandes vertientes, las cuales hacen parte del derecho penal en Colombia, para luego evaluar si están directamente relacionadas con la realidad jurídica y social del país. Las vertientes objeto de análisis son la politica criminal del enemigo, o populismo punitivo, y la politica criminal minimalista o de los derechos humanos.

\section{Política criminal del enemigo (populismo punitivo)}

Populismo punitivo es un concepto ideado por el profesor Anthony Bottoms (1995), que señala la motivación política tras la creación de tipos penales o el incremento de las penas de los delitos ya tipificados con base en que eso hace que el criminal se cohíba de delinquir y reduce, por tanto, la criminalidad.

Al respecto, Rodrigo Uprimny ha expresado:

Resulta, entonces, políticamente popular promover esas iniciativas de endurecimiento punitivo. $\mathrm{Y}$ en eso consiste lo que la sociología jurídica ha 
llamado el "populismo punitivo": creer (y hacer creer) que el incremento de las penas es la forma apropiada de enfrentar problemas sociales complejos, como la violencia contra los nińos. (2011, párr. 4)

El profesor Juan Sotomayor Acosta ha manifestado que se debe matizar el uso de la expresión en nuestro contexto. Es así como hace referencia al populismo punitivo “a la colombiana” debido a que su nacimiento difiere de los motivos por los cuales surgió en otros países:

No es resultado del desmonte de un Estado de bienestar impensable en un país como Colombia, ni es tampoco la respuesta a un aumento real de la criminalidad, mucho menos a un aumento de confianza en el sistema penal y ni siquiera a una política criminal orientada realmente a un mayor control de la delincuencia. (2013, pp. 51-52)

Esta práctica político-electoral ha desplazado el problema de la criminalidad al hacinamiento dado que el sistema penitenciario y carcelario del país no ha sido preparado ni actualizado conforme a los cambios que los legisladores han realizado y desean realizar en busca de la aceptación y preferencia de los electores.

Ahora bien, para entender un poco más a qué nos referimos con populismo punitivo es necesario precisar que se trata de políticas para evitar la delincuencia y reducir los problemas penales bajo el siguiente esquema: i) acrecentar las penas suponiendo que esto evitará que las personas cometan delitos; ii) esperar que las penas jurídicas ayuden a delimitar el concepto de moral que debe aplicarse en la sociedad y de esa forma reforzar el ideal de bien general; iii) creer que lo anterior va a asegurar votos en futuras elecciones dado que las personas están de acuerdo con establecer penas ejemplares y ejecutar mecanismos de exclusión para las personas que no siguen los lineamientos generales de la sociedad (Larrauri, 2007, p. 10).

Así, es posible establecer que esta es una de las causas del hacinamiento carcelario, toda vez que se están creando delitos y aumentando penas, lo que causa caos en el aparato judicial y el sistema penitenciario. Ello lleva a que el Estado no tenga la capacidad de cuidar de manera idónea a los reclusos y vulnere sus derechos. Adicionalmente el 
Estado debe afrontar todo tipo de consecuencias, desde disminución del patrimonio público hasta la pérdida de la credibilidad de los actuales gobiernos (Quiroz, 2014).

\section{Política criminal minimalista o de los derechos humanos}

Hace referencia a un enfoque de tipo preventivo sobre política pública. En este sentido, la finalidad de dichas políticas es reducir al máximo la conflictividad. En este caso sería adecuado utilizar la postura de Binder, quien considera que todas las legislaciones — "la económica, la educativa, la de salud y la de relaciones exteriores, bajo su doble modalidad de la defensa y la diplomacia” (2011, p. 161) - deben estar conjuntamente orientadas a crear una política de gestión de la conflictividad tal que el último recurso sería la implementación de medios violentos por parte del Estado.

$\mathrm{Al}$ respecto, autores como Abramovich, Bovino y Courtis (2007, p. 255) manifiestan que para evitar que estas políticas permeen el ámbito jurídico y lo perjudiquen es necesario atender estrictamente a los estándares generales del derecho internacional de los derechos humanos: este surte un marco doctrinario que delimita principios y reglas básicos por fuera de los cuales nadie podrá moverse, de modo que provee directrices adecuadas tanto para la formulación como para la ejecución de las políticas públicas.

En ese sentido, los Estados han determinado que en materia de política criminal se deben aplicar los estándares generales de los Desc (derechos económicos, sociales y culturales) con el objeto de proveer efectividad: i) contenido mínimo de los derechos, ii) utilización al máximo de los recursos disponibles, iii) progresividad y no regresividad, iv) igualdad y no discriminación, v) acceso a la justicia y mecanismos de reclamo, vi) producción de información y acceso y vii) participación de los sectores afectados en el diseño de políticas públicas (Abramovich y Patuassi, 2010).

En todo caso, puede llegarse a ejecutar la política criminal siempre y cuando se cumpla con la aplicabilidad de unos mínimos en los derechos humanos de los ciudadanos. Toda política que se pretenda aplicar debe tener un estudio previo de validez y legalidad, el cual debe ser estricto para que no se vea afectado el bloque de constitucionalidad. 


\section{Conclusiones}

El hábeas corpus en Colombia a partir de la Constitución Política de 1991 generó un revuelo en el mundo constitucional pues hizo parte del cambio que permitió el paso del Estado de derecho a un Estado social de derecho determinado por la importancia de la aplicación y efectividad de los derechos humanos. En ese sentido, con dicha carta magna se logró la institución de unos derechos fundamentales para el individuo, que contaran con especial protección. Con ocasión de ello se estipuló que tales derechos debían restringirse lo menos posible, y, en caso de tener que hacerlo, debía disponerse de un amplio fundamento jurídico y legal que determinara el porqué de dicha limitación. Estas consecuencias permitieron que el Hábeas corpus no solo se entendiera como una acción constitucional encargada de evitar privaciones de la libertad arbitrarias, sino en sí mismo como un derecho que debe preservarse en el individuo. Por supuesto, ello genera una carga jurídica al Estado puesto que obliga a la administración de justicia a realizar un estudio hermenéutico-jurídico en el cual se decida si es procedente, en cada caso específico, imponer la privación de la libertad para evitar así la vulneración de los derechos humanos.

Por otro lado, es importante resaltar que en caso de privar a una persona de la libertad se crea una relación de sujeción especial entre el detenido y el Estado: este se convierte en el garante de aquel, razón por la cual es el responsable de protegerlo de manera integral. En el caso específico de Colombia, y atendiendo lo evidenciado en este trabajo de investigación, es posible establecer que nuestro Estado aún no se encuentra en la capacidad estructural ni funcional de cumplir con tal compromiso, como lo evidencian las vulneraciones atroces a los derechos humanos ocurridas en nuestros centros penitenciarios.

Como se mencionó anteriormente, la Corte Suprema de Justicia de Honduras concedió la acción de hábeas corpus solicitada por la Fiscalía Especial de Derechos Humanos en favor de siete presos de la Celda Veinte o Celda de Castigo de la Penitenciaría Nacional de San Pedro Sula (Departamento de Cortés), y ordenó la libertad de los detenidos al determinar que habían sido sometidos a tratos crueles, inhumanos y degradantes. Esto constituye un antecedente que confirma que el hábeas corpus es una garantía constitucional para la protección de derechos fundamentales vulnerados 
por el hacinamiento carcelario. Lo anterior abre la posibilidad de incoar en Colombia una acción de hábeas corpus correctiva, que permita finalizar la vulneración de los derechos fundamentales de quienes sufren las consecuencias de la crisis carcelaria del país. No obstante, si se considera que la libertad no es pertinente porque quienes la obtengan podrían constituir un riesgo para la sociedad, la ley contempla medidas alternativas como la prisión domiciliaria. Tal y como se mencionó anteriormente, no hay nada que impida que un juez constitucional conceda la detención domiciliaria incluso para aquellos detenidos que no cumplan objetivamente la totalidad de los requisitos establecidos.

Cabe resaltar que el derecho penal representa la facultad sancionatoria del Estado y ha de tenerse en cuenta como ultima ratio, de modo que debe analizarse cuidadosamente para cada caso la idoneidad, necesidad y proporcionalidad de la pena en aras de controlar el ejercicio del poder punitivo. Así las cosas, las penas deben ser razonables y han de buscar la resocialización del infractor para una adecuada reincorporación a la vida en comunidad. Sin embargo, difícilmente podrá lograrse tal fin cuando bajo la "protección" de quien ha de resocializarse se esconde la mayor vulneración a la vida y a la dignidad humana.

Conforme a lo anterior, es importante tener presente que no toda comisión de un hecho punible debe tener como resultado la privación de la libertad pues la misma ley estipula medidas sustitutivas. De igual forma, debe tenerse en cuenta que la detención preventiva es excepcional y ha de aplicarse solo cuando la situación fáctica y jurídica permita establecer que es necesaria a fin de asegurar la comparecencia del indiciado y la no interferencia en el desarrollo de la investigación.

Finalmente, luego de analizada la información recolectada durante la presente investigación se concluye que el hábeas corpus es el mecanismo idóneo para la protección del derecho a la libertad. No obstante, ha de tenerse en cuenta el pronunciamiento de la Corte Constitucional mediante Sentencia C-187/2006, en el cual se manifiesta que el radio de protección se expande a otros derechos fundamentales íntimamente relacionados con aquel, de modo que se constituye un mecanismo de protección integral. Igualmente, considérese lo establecido en la Ley Estatutaria 1095 de 2006, que amplía el campo de aplicación del hábeas corpus 
pasando del momento de la captura a la privación de la libertad — que comprende incluso la reclusión en centro carcelario o penitenciario-. Así las cosas, la acción constitucional y derecho fundamental del hábeas corpus puede ser instaurada como mecanismo idóneo para buscar el respeto de los mínimos vitales a través de la solicitud de libertad del individuo que se encuentra privado de esta en condiciones deplorables e inhumanas derivadas del hacinamiento carcelario. $O$ por lo menos para pedir que la pena sea cumplida en un lugar que asegure el respeto por la dignidad humana, la vida y la salud, entre otros.

Al fin y al cabo, el Estado colombiano, como parte de organizaciones internacionales y en atención a los compromisos adquiridos en los diversos acuerdos y pactos suscritos e integrados a la Constitución Política mediante el bloque de constitucionalidad, está obligado a respetar los derechos humanos y fundamentales inherentes a cada individuo que hace parte del territorio y a velar por el cumplimiento de los fines esenciales promulgados en el art. 2 de nuestra Constitución Política

\section{REFERENCIAS}

Abramovich, V., Bovino, A. y Courtis, C. (2007). La aplicación de los tratados sobre derechos humanos en el ámbito local. La experiencia de una década. Buenos Aires: Del Puerto. DOI: https://doi.org/10.2307/j.ctt1zgwk33.6

Abramovich, V. y Pautassi, L. (2010). La medición de derechos en las politicas sociales. Buenos Aires: Del Puerto.

Alto Comisionado de las Naciones Unidas para los Derechos Humanos. Oficina en Colombia (2001). Informe centros de reclusión en Colombia: un estado de cosas inconstitucionaly de flagrante violación de derechos humanos. Bogotá: autor. DOI: https://doi.org/10.2307/j. ctt1ffir6g.7

Asamblea General de la ONU (1948). Declaración Universal de Derechos Humanos. Resolución 217 A (III). París. Recuperado de http://www.un.org/es/documents/udhr/. 
Asamblea General de la ONU (1966). Pacto Internacional de Derechos Civiles y Politicos. Resolución 2200 A (XXI). DOI: https://doi.org/10.1163/2210-7975_hrd-0578-0101

Binder, A. (2011). Análisis politico criminal. Buenos Aires: Astrea.

Bottoms, A. (1995). Philosophy and politics of punishment and sentencing. Oxford: OUP.

Cárdenas, J. (2009). Régimen de libertad y hábeas corpus. Revista del ICDP, 35. Recuperado de https://goo.gl/M5iM9Q

Consejo Superior de Política Criminal (2015). Relatoría. Foro Nuevo Estado de Cosas de Inconstitucionalidad. Recuperado de https://goo.gl/wBQCTP

Corte Constitucional. Sentencia T-153 (1998). M. P. Eduardo Cifuentes Muñoz.

Corte Constitucional. Sentencia C-620 (2001). M. P. Jaime Araújo Rentería.

Corte Constitucional. Sentencia C-646 (2001). M. P. Manuel José Cepeda Espinosa.

Corte Constitucional. Sentencia C-187 (2006). M. P. Clara Inés Vargas Hernández.

Corte Constitucional. Sentencia T-023 (2010). M. P. Humberto Antonio Sierra Porto.

Corte Constitucional. Sentencia C-936 (2010). M. P. Luis Ernesto Vargas Silva.

Corte Constitucional. Sentencia T-388 (2013). M. P. María Victoria Calle Correa.

Corte Suprema de Honduras, Sala Constitucional. Sentencia expediente 711-06 (7 de marzo de 2007).

Forero, J. (2014). El valor superior de la justicia en la Unión Europea. Especial referencia al Estado constitucional social y democrático de derecho español. Verba Iuris, 31, 91-114. DOI: https://doi.org/10.18041/0121-3474/verbaiuris.31.59 
García, D. (1973). Los orígenes del hábeas corpus. Derecho PUCP, 31, 48-59.

Larrauri, E. (2007). Populismo punitivo... y cómo resistirlo. Revista de Estudos Criminais, $7(25), 9-25$.

López Benítez, M. (1994). Naturaleza y presupuestos constitucionales de las relaciones especiales de sujeción. Córdoba, España: Civitas.

Mayer, O. (1982). Derecho administrativo alemán. Tomo IV. Buenos Aires: Depalma.

Molina, Y. (2016). Derecho penal del enemigo y dignidad humana. Verba Iuris, 11(36), 135 146. DOI: https://doi.org/10.18041/0121-3474/verbaiuris.36.1018

OEA (1969). Convención Americana sobre Derechos Humanos. San José (Costa Rica). Recuperado de https://goo.gl/9n1eNr

Pérez, A. (2013). El agotamiento previo de la acción de inconstitucionalidad para acceder al Sistema Interamericano de Protección de los Derechos Humanos. Verba Iuris, 30, 61 82. DOI: https://doi.org/10.18041/0121-3474/verbaiuris.30.2148

Quiroz, M (2014). Acercamiento a las “oposiciones paradigmáticas” entre neoconstitucionalismo y positivismo jurídico. Revista Iusta, 41(2), pp. 77-97. DOI: https://doi. org/10.15332/s1900-0448.2014.0041.03

República de Colombia (1991). Constitución Politica de Colombia.

Sotomayor Acosta, J. (2013). Las recientes reformas penales en Colombia: un ejemplo de irracionalidad legislativa. Nuevo Foro Penal, 3(71), 13-66. Recuperado de https:/goo. gl/3R $4 \mathrm{xuG}$

Uprimny, R. (12 de septiembre de 2011). La impunidad, el desespero y el populismo punitivo. El Espectador. Recuperado de https://goo.gl/KLtWLx

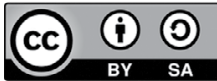

